\author{
Sin Yee Goh and Sze-Ying Thong* \\ Associate Consultant, Singapore General Hospital, \\ Department of Anesthesia, Singapore \\ Dates: Received: 27 October, 2014; Accepted: 28 \\ February, 2015; Published: 01 March, 2015 \\ *Corresponding author: Sze-Ying Thong, \\ Associate Consultant, Singapore General Hospital, \\ Department of Anesthesia, Singapore, E-mail: \\ thongszeying@gmail.com \\ www.peertechz.com \\ ISSN: 2455-3476
}

\section{Case Report \\ Cerebrospinal Fluid Cutaneous Fistula after Uneventful Epidural Analgesia}

\section{Introduction}

A cerebrospinal fluid cutaneous fistula is rarely a complication of epidural analgesia. Cases in adults and children have been reported after complicated epidural catheter insertion in spinal surgery [1], CSF lumbar drain insertion [2] and in immunocompromised patients [3]. We report a case of cerebrospinal fluid cutaneous fistula after uneventful thoracic epidural catheter insertion and discuss its diagnosis and management.

\section{Case}

The patientwas a 45 -year-old patient with long standing peptic ulcer disease and multiple gastric surgeries. The patient's surgical history included agastrectomy with Bilroth II anastomosis, which was converted to a Roux-en-Y anastomosis in 2008. Since then, the patient suffered persistent abdominal pain, nausea and vomiting as a result of delayed gastric emptying due to anastomosis narrowing. Revision of his Roux-en-Y anastomosis was performed in 2011. The patient also required a subsequent endoscopic dilation that was complicated by anastomotic leakage requiring further surgical management.

The patient developed chronic pain related to the gastric issues and previous multiple surgeries. The current medications include fentanyl patch $50 \mathrm{mcg} / \mathrm{h}$ q $72 \mathrm{~h}$, hydromorphone $2-4 \mathrm{mg}$ tid, pregabalin $50 \mathrm{mg}$ bid, gabapentin $300 \mathrm{mg}$ bid, naproxen $500 \mathrm{mg}$ bid and acetaminophen 500mg q6h.

The patient was scheduled for laparotomy, resection of distal gastric remnant, previous Roux-en-Y limb, anastomosis reconstruction using proximal jejunal loop and stomach.The patient had previous epidural analgesia for the gastric surgery and consented to receive epidural analgesia prior to the upcoming laparotomy. An experienced anesthesiologist inserted the Duraflex ${ }^{\circledR}$ epidural catheter (Smiths Medical, Kent, United Kingdom) in the T7-T8 level on first attempteasily using the loss of resistance to saline technique via a 17G Tuohy needle. Test dose of lidocaine $2 \% 4 \mathrm{ml}$ and bupivacaine $0.25 \% 3 \mathrm{ml}$ achieved T6-T12 sensory blockade. Surgery proceeded uneventfully and pain control was satisfactory perioperatively with an epidural infusion of ropivacaine $0.2 \%$ (with fentanyl $2 \mathrm{mcg} / \mathrm{ml}$ ) at $8 \mathrm{ml} / \mathrm{h}$. There was no motor block, respiratory compromise or hemodynamic instability.

The patient was seen daily by the acute pain team and pain relief from the epidural analgesia was good. Bilateral sensory block from T4 to L1 was consistently achieved without loss of motor strength. Perioperatively, the patient was continued onthe regular dose of fentanyl patch and was gradually commenced on the patient's regular oral analgesia on postoperative day 2 .

On postoperative day 3 , the patient suffered breakthrough pain due to migration of the catheter out of the epidural space. The epidural catheter was removed uneventfully. The patient was started on subcutaneous hydromorphone $2-4 \mathrm{mg}$ q2h. The patient was ambulating without difficulty.

On day 4 , the anesthetic team was called to review the patient as clear fluid had been observed discharging continuously from the previous epidural insertion site. It was consistently soaking the dressing and required frequent changes. The fluid was collected and tested positive for glucose. The patient reported no symptoms of headache or photophobia and was afebrile.There was no neurological deficit and the epidural site appeared clean. A provisional diagnosis of epidural-cutaneous or cerebrospinal fluid cutaneous fistula was made. He was managed conservatively and monitored closely. The patient was continued on his surgical prophylaxis, cefazolin, but no additional antibiotics were prescribed. The fluid discharge resolved with pressure dressing on postoperative day 6 . The patient was discharged on postoperative day 8 and seen during the next surgical follow up without further complication.

\section{Discussion}

Cerebrospinal fluid fistula has been described as a consequence of neuraxial procedures such as spinal surgery [1] and intrathecal catheters and drains [2,4]. However, only a handful of case reports exist describing it in anesthetic practice, both in adults $[3,5,6]$ and children [7]. 
Table 1: Perioperative blood investigations.

\begin{tabular}{|l|c|c|}
\hline & Pre operative & Post operative day 1 \\
\hline Hemoglobin $(12.0-16.0 \mathrm{~g} / \mathrm{dl})$ & 9.9 & 9.0 \\
\hline Urea $(2.8-7.7 \mathrm{mmol} / \mathrm{l})$ & 5.8 & 2.8 \\
\hline Sodium $(135-145 \mathrm{mmol} / \mathrm{l})$ & 143 & 134 \\
\hline Potassium $(3.3-4.9 \mathrm{mmol} / \mathrm{l})$ & 3.3 & 3.6 \\
\hline Chloride $(96-108 \mathrm{mmol} / \mathrm{l})$ & 109 & 102 \\
\hline Bicarbonate $(19.0-31.0 \mathrm{mmol} / \mathrm{l})$ & 22 & 23 \\
\hline Creatinine $(40-85 \mathrm{umol} / \mathrm{l})$ & 46 & 36 \\
\hline
\end{tabular}

Table 2: Perioperative arterial blood gas.

\begin{tabular}{|c|c|c|c|}
\hline & $\begin{array}{l}\text { Immediatelypost } \\
\text { intubation }\end{array}$ & $\begin{array}{c}\text { Th into surgery after } \\
50 \mathrm{ml} 8.4 \% \text { sodium } \\
\text { bicarbonate }\end{array}$ & $\begin{array}{c}\text { After transient } \\
\text { apnea post } \\
\text { extubation }\end{array}$ \\
\hline Time, $\mathrm{h}$ & 1752 & 1837 & 1946 \\
\hline $\mathrm{pH}$ & 7.189 & 7.432 & 7.179 \\
\hline $\mathrm{pCO}_{2}, \mathrm{mmHg}$ & 32.6 & 29.2 & 46.2 \\
\hline $\mathrm{pO}_{2}, \mathrm{mmHg}$ & 322 & 295 & 245 \\
\hline $\begin{array}{l}\text { Base excess, } \\
\mathrm{mmol} / \mathrm{l}\end{array}$ & -16 & -5 & -11 \\
\hline $\mathrm{HCO}_{3}, \mathrm{~mol} / \mathrm{l}$ & 12.4 & 19.5 & 17.2 \\
\hline
\end{tabular}

It has been suggested that the finding of fluid discharging from a previous epidural site following its removal may be far more common than is suggested in current literature [8]. The nature of such a fluid leak, however, may often be attributed to subcutaneous edema or local anesthetic solution, which may pool in the epidural or subcutaneous space and be discharged via the skin tract created by the epidural catheter. Accompanying features of post dural puncture headache $(\mathrm{PDPH})$ such as postural headache, nausea, vomiting and visual or auditory alterations may suggest leakage of CSF with resultant intracranial hypotension. However, in the absence of these features, as it was in this case, the diagnosis is tricky. Analyses of the fluid for the presence of glucose and low protein levels are quick and easy tests that have low sensitivity in this situation but are nevertheless clinically useful. For a more specific tool, testing for the presence of beta- 2 transferrin has been utilized in the diagnosis of CSF rhinorrhea and otorrhea in the neurosurgical setting [9]. Despite being more timeconsuming to perform, it is able to identify CSF on small amounts of fluid and may have been helpful in the diagnosis of CSF leak in this case [10]. The presence of beta-trace protein (prostaglandin D synthase) is another test that has been described [11]. Unfortunately, neither test was performed in this case.

It is unknown why this patient developed this complication. As it is so rare, the risk factors that lead to its development are largely unknown. However, it is presumed that a CSF leak is more likely in the event of an intentional dural breach, such as in the case of lumbar puncture [12], subarachnoid blockade or CSE [6], or an inadvertent dural puncture during epidural catheter insertion. This was a straightforward epidural insertion and the patient showed no signs of PDPH after. Possible factors that could contribute to delayed healing of the tract include immune compromise (including systemic steroid usage) $[3,6,13]$, multiple attempts at the same vertebral level using the same needle, and the use of epidural steroids [14]. Again none of these apply to our patient. A plausible explanation could be an inadvertent breach of the dura during epidural insertion. The defect could have been partially occluded by the epidural catheter and subsequent LA injected through the catheter. This tamponade effect would have been lost with the removal of the epidural catheter, resulting in a fluid leak. It is also possible that the nature of the fluid could be CSF, local anesthetic solution or a combination of both. Though the presence of glucose in the fluid suggests that it is CSF, it is impossible to conclusively determine the nature of the fluid without more specific tests.

\section{Management}

As this is a rare condition, there is no standardized treatment and management options vary. Conservative management has been effective in some of the cases described, and includes sterile pressure dressing as well as bed rest in positions designed to reduce CSF leakage, such as slight Trendelenburg position [4], prone position and lateral position with hip flexion [5]. In cases where CSF drainage has been high, cutaneous stitching of the defect left by the epidural insertion has been advocated by some, believing that suturing might close the defect, allowing the accumulating fluid to create a tamponade effect and promote healing.Stitching might also potentially reduce the risk of meningitis, though there is currently no evidence to support such a claim $[10,14]$.

Our patient did not have any feature of infection or neurological deficits and it was decided that expectant treatment was best in the first few days provided that the discharge did not worsen and he remained asymptomatic and non-toxic. He was advised bed rest andcontinued on his surgical antibiotic prophylaxis, cefazolin. The use of prophylactic antibiotics for the purpose of preventing infection after a cerebrospinal cutaneous fistula is disputed, but is generally not advocated in an afebrile, non-toxic patient $[5,14]$.

Persistent fluid leak may warrant further treatment. The main concern of an untreated CSF leak is meningitis. Epidural blood patch has been used effectively in several cases, both in adults $[3,13]$ and children[2,7], and has been described to provide almost immediate relief to both CSF leakage and post dural puncture headache in a matter of hours. If the fluid leak fails to resolve after epidural blood patch and figure of eight stitches over the fistula site, Kumar et al have described successful treatment using subarachnoid catheter for CSF drainage [2].

Due to the rarity of this condition, follow-up of post epidural patients should be meticulous by an experienced team. Definite diagnosis may be difficult as in our case and a high index of suspicion is required. In the absence of infection, neurological deficit and features of durabreach, conservative treatment was reasonable in this patient. A case of CSF-cutaneous fistula complicated by pseudomonas meningitis was successfully treated conservatively with bed rest and antibiotics [6].

\section{Conclusion}

Cerebrospinal fluid cutaneous fistula is a rarebut potentially 
devastating complication of epidural and neuraxial analgesia. A high index of suspicion is necessary. Analysis for glucose and protein may offer a quick way of identifying the fluid, but more specific tests such as beta- 2 transferrin should be used for confirmation. In the absence of symptoms suggesting PDPH or meningitis, conservative management alone might be sufficient. In other situations, cutaneous stitching or epidural blood patches have been found effective.

\section{References}

1. Maycock NF, van Essen J, Pfitzner J (1994) Post-laminectomy cerebrospinal fluid fistula treated with epidural blood patch. Spine (Phila Pa 1976) 19: 2223 2225 .

2. Kumar V, Maves T, Barcellos W (1991) Epidural blood patch for treatment of subarachnoid fistula in children. Anesthesia 46: 117-118.

3. Abaza KT, Bogod DG (2004) Cerebrospinal fluid-cutaneous fistula and pseudomonas meningitis complicating thoracic epidural analgesia. $\mathrm{Br} \mathrm{J}$ Anaesth 92: 429-431.

4. Katz J (1984) Treatment of a subarachnoid-cutaneous fistula with an epidura blood patch. Anesthesiology 60: 603-604.

5. Lieberman KM, Tourtellotte WW, Newkirk TA (1971) Prolonged post-lumbar puncture cerebrospinal fluid leakage from lumbar subarachnoid space demonstrated by radioisotope myelography. Neurology 21:925-929.
6. Jawalekar SR, Marx GF (1981) Cutaneous cerebrospinal fluid leakage following attempted extradural block. Anesthesiology 54: 348-349.

7. Hosu L, Meyer MJ, Goldschneider KR (2008) Cerebrospinal fluid cutaneous fistula after epidural analgesia in a child. RegAnesth Pain Med 33: 74-76.

8. Bansal S (2004) Fluid leak from epidural puncture site: a diagnostic dilemma. AnesthAnalg 99: 1577.

9. Marshall AH, Jones NS, Robertson IJ (1999) An algorithm for the management of CSF rhinorrhoea illustrated by 36 cases. Rhinology 37:182-185.

10. Chan BO, Paech MJ (2004) Persistent cerebrospinal fluid leak: a complication of the combined spinal-epidural technique. AnesthAnalg 98: 828-830.

11. Petereit HF, Bachmann G, Nekic M, Althaus H, Pukrop R (2001) A new nephelometric assay for beta-trace protein (prostaglandin $D$ synthase) as an indicator of liquorrhoea. J NeurolNeurosurg Psychiatry 71: 347-351.

12. Ball CG, D'Alessandro FT, Rosenthal J, Duff TA (1975) Case history number 86: an unusual complication of lumbar puncture: a CSF-cutaneous fistula. AnesthAnalg54: 691-694.

13. Howes J, Lenz R (1994) Cerebrospinous fluid cutaneous fistula. An unusual complication of epidural anaesthesia. Anesthesia 49: 221-222.

14. Tsai A (2014) Persistent cerebrospinal fluid-cutaneous fistula after epidural analgesia: a case report and review of literature. Journal of Anesthesiology and Clinical Science. 